HUMERES NOGUER, Héctor y HALPERN MONTECINO, Cecily: La unificación de jurisprudencia laboral. Contenido teórico, análisis doctrinal y temático, Thomson Reuters, Santiago de Chile, 2015, 327 páginas.

Los autores, un matrimonio de reconocidos abogados y destacados profesores de Derecho laboral de la Universidad de Chile, formadores de varias generaciones de juristas, ofrecen a la comunidad jurídica chilena un trabajo monográfico sobre el recurso de unificación de jurisprudencia. No es el primer libro que se ha publicado en Chile sobre esta materia, sin embargo, supera largamente el carácter de mera compilación de fallos de las obras precedentes, pues desarrolla en sus más de trescientas páginas un análisis dogmático del medio de impugnación, contextualizado dentro del sistema recursivo, sus antecedentes históricos y comparados, para luego ofrecer una cuidada sistematización de la jurisprudencia de unificación de la Corte Suprema, comentada críticamente.

La obra se compone de dos partes. La primera parte se subdivide en tres capítulos.

El primero, titulado "Los recursos laborales. Breve examen del antiguo y nuevo procedimiento del trabajo" introduce conceptualmente al sistema de impugnaciones, enumera sus fuentes formales y esboza una descripción del mismo pre y post reforma procesal laboral.

El capítulo segundo, se titula "El recurso de unificación de jurisprudencia laboral” y explica la noción de precedente judicial, su clasificación y relevancia respeto de la materia analizada. Enseguida rastrea los antecedentes de la figura en la ley procesal laboral española, específicamente en el recurso de casación para la unificación de doctrina, que describe someramente. Este capítulo concluye con una pormenorizada descripción de las vicisitudes legislativas, ligadas primeramente al recurso de apelación en contra de la sentencia definitiva y, luego, al recurso de nulidad que lo sustituyó y que finalmente incidieron en la formulación del recurso de unificación tal y como se le conoce hoy día.

El tercer capítulo se denomina "Estudio particular del recurso de unificación de jurisprudencia (RUJ) en la legislación laboral chilena. Como anticipa su título, aquí los autores realizan el análisis dogmático-jurídico de la regulación positiva de este medio impugnativo. Explican su concepto, características, causales, tramitación, contenido y la resolución del recurso.

La segunda parte del libro se subdivide en tres capítulos, correspondiendo el último a las conclusiones.

El capítulo primero se titula "Estudio jurisprudencial desde el año 2009 al 30 de abril de 2015. Criterios doctrinarios contenidos en RUJ acogidos y rechazados, categorizados por institución laboral y fecha". Los autores sistematizaron todas las sentencias dictadas por la Excma. Corte Suprema en el referido lapso en veintiún temas (Ámbito de aplicación del Código del Trabajo; sujetos de la relación laboral; contenido ético del contrato de trabajo; jornada superior a 30 horas; remuneración; terminación; nulidad de despido; finiquito; fuero; subcontratación; Estatuto Docente; accidente del trabajo; prescripción; permisos sindicales; práctica antisindical; reemplazo en huelga; contrato colectivo; acrecimiento de montepío; presupuestos fácticos; revisión de la prueba en el recurso de nulidad y rechazo del RUJ por requisitos de forma). En cada uno de los respectivos acápites se efectúa un extracto de la doctrina sentada por la Corte y se registra algunas vueltas de timón tras el cambio en la integración de la Cuarta Sala. 
El capítulo segundo se intitula "Análisis de las tendencias más relevantes extraídas de los criterios doctrinarios examinados", donde los autores se concentran en doce materias que ellos consideran representan las tendencias más relevantes y de mayor significación desde el punto de vista de los justiciables con el objetivo de someterlas a crítica. Sin perjuicio de que los autores coinciden con algunos de los criterios comentados, sus análisis son mayoritariamente discrepantes de los introducidos por la Cuarta Sala tras su nueva integración (2014), defendiendo un apego estricto a la ley frente a la tendencia activista que comienza a imponerse en dicha Sala.

En el capítulo tercero y final de la obra, se expone las conclusiones, primero, en relación con ciertas características formales del recurso que los autores decantan a partir de la comprensión de la propia Corte Suprema sobre esta vía impugnativa. En seguida los autores exponen su reflexión sobre las bondades y defectos de la configuración legal del RUJ, su funcionamiento práctico y aporte social. A partir de datos estadísticos demuestran que la introducción de este recurso significó una restricción ostensible en el acceso al Tribunal Supremo, lo que en su concepto conspira contra el derecho al acceso a la tutela judicial efectiva y al debido proceso. Critican también lo que ellos estiman una comprensión defectuosa del efecto relativo de las sentencias que obsta a una real unificación de la jurisprudencia laboral, partiendo por la propia Cuarta Sala que ha modificado criterios previamente unificados. Abogan desde la igualdad en la aplicación del Derecho por un grado de mayor vinculación al precedente, de manera que lo que los jueces digan sea previsible. Reiteran su crítica al activismo judicial y afirman que los jueces -funcionarios no electos por elección popular directa- no deben fallar conforme a sus propias convicciones jurídico-personales, sino que de acuerdo a la manifestación de la voluntad soberana que se expresa en la ley y a la jurisprudencia. Finalizan con una recomendación de lege ferenda en orden a que se considere en forma expresa la obligatoriedad del autoprecedente y respecto de los tribunales inferiores, la sujeción a los considerandos ratio decidendi de los fallos de la Corte Suprema, sin perjuicio de la posibilidad de revisar los argumentos decisorios, en razón de nuevos fundamentos jurídicolegales que considere atendibles el máximo tribunal.

El libro contiene finalmente tres extensos anexos, los dos primeros con fichas jurisprudenciales de recursos acogidos entre 2009 y 2015 y recursos rechazados entre 2013 y 2015. El tercer anexo contiene estadísticas sobre el RUJ desde 2009 a abril del 2015.

La obra de los profesores Humeres y Halpern es el resultado de una investigación prolija y de un meditado análisis de las fuentes consultadas. Ofrece al lector una comprensión muy completa del recurso de unificación, tanto en su estructura como en su operatividad y un utilísimo material de sentencias: exhaustivo en su compilación, preciso en su extracto y certero en su crítica. Se convertirá probablemente en una obra de referencia obligada para los investigadores y en una herramienta insustituible para el uso forense.

\section{Claudio Palavecino Cáceres*}

\footnotetext{
* Abogado. Profesor Asistente del Departamento de Derecho del Trabajo y la Seguridad Social, Facultad de Derecho, Universidad de Chile. Contacto: cpalavec@derecho.uchile.cl
} 